\title{
Asymmetric Price Transmission of World Prices to Kenyan Tea Market
}

Vincent Ngeno ( $\square$ vcngeno@gmail.com )

Research

Keywords: Tea markets, threshold cointegration, M-TAR model, asymmetric price transmission

Posted Date: March 12th, 2020

DOI: https://doi.org/10.21203/rs.3.rs-16961/v1

License: (1) (i) This work is licensed under a Creative Commons Attribution 4.0 International License. Read Full License 


\section{Asymmetric Price Transmission of World Prices to Kenyan Tea Market}

Vincent Ngeno

Department of Agricultural Economics \& Resource Management

Moi University, Kenya

vengeno@gmail.com 


\title{
Asymmetric Price Transmission of World Prices to Kenyan Tea Market
}

\begin{abstract}
The use of asymmetrical threshold cointegration test is adopted in this study to investigate whether any significant relationship or asymmetric adjustment exists in transmission of prices between the world tea market and domestic prices in Kenya. The empirical results obtained are as follows. First, we verify a close link between the Kenya's tea price and its international counterparts under the current period of market liberalization. Second, empirical results demonstrate that in both long run and short run, the price transmission between world tea market and Kenyan domestic market are nonlinear and asymmetric, suggesting long run and short run dynamic inefficiencies and presence of transaction costs.
\end{abstract}

Key words: Tea markets; threshold cointegration; M-TAR model and asymmetric price transmission.

JEL classification: C32, Q13, Q17

\section{Introduction}

Kenya is the world's third largest producer of tea and the tea industry provides livelihoods for hundreds of thousands of rural Kenyans. Tea is Kenya's leading export commodity. During early 1990s, Kenya liberalized agricultural trade policies to integrate tea farmers into international tea markets. These policies are intended to benefit domestic tea farmers, as market integration allows them to respond to market signals and make optimal production decisions. A key requirement for successful integration is that the transmission, or pass-through, of world price signals to domestic producers be high (Baquedano, Liefert, \& Shapouri, 2011). However, world price changes might be transmitted to domestic tea producers unevenly. This suggests the existence asymmetries in price transmission which may negatively affect tea farmers.

Asymmetry in price transmission in an integrated market refers to the phenomenon that occurs when a market responds to the price increases in a different way from its response to price decreases (Korale Gedara, Ratnasiri, \& Bandara, 2016). Existence of asymmetric price transmission can be a manifestation of market failure, which induces an imperfect pass through of price signals between international markets and domestic producer prices (Fiamohe, Alia, Bamba, Diagne, \& AmovinAssagba, 2015). Generally, it is assumed that asymmetry in price transmission between markets occurs when transaction costs are high (Balcombe, Bailey, \& Brooks, 2007). Regression and cointegrationbased tests have been criticized recently for their ignorance of transactions costs. The presence of transaction costs, which typically are unobservable to the empirical researcher, may lead to a "threshold" within which prices are not linked to one another (Goodwin \& Piggott, 2001).

Recognition of the important but often neglected role of transaction costs has led to the application of new empirical approaches which explicitly recognize the influence of transaction cost on spatial market linkages. The most common approach used in the recent literature makes use of the threshold effect to take account of transaction costs, asymmetries and nonlinearities (Abdulai, 2000; Balcombe et al., 2007). Threshold autoregression models recognize thresholds, caused by transaction costs, that deviations must exceed before provoking equilibrating price adjustments which lead to market integration. Threshold effects occur when larger shocks (i.e, shocks above some threshold) bring about a 
different response than do smaller shocks (Goodwin \& Piggott, 2001). The resulting dynamic response may involve various combinations of adjustments from alternative regimes defined by the thresholds.

Several studies have documented the presence of price asymmetries in the transmission of price shocks of export crops from world market to domestic producers in developing countries (Mai, Shakur, \& Cassells, 2018; Mofya-Mukuka \& Abdulai, 2013; Shrinivas \& Gómez, 2016). However, the literature has not examined asymmetries and thresholds in the price transmission between the world tea market and domestic prices in Kenya. This study is motivated, in part, by unobservable transactions costs and the important influence that their presence may exert on equilibrium spatial price relationships.

The objective of this study is to examine the dynamic relationship between international and Kenyan domestic tea prices by exploring the possibility of cointegration with asymmetric adjustments. In line with Mighri and Mansouri (2016) and Shen, Chen, and Chen (2007), we adopt the threshold autoregressive (TAR) and momentum threshold autoregressive (M-TAR) models developed by (Enders \& Siklos, 2001) to conduct the analysis. These allow for negative shocks, or deviations from equilibrium, to have different effects from those that are positive. They are related to, but distinct from, models suggested by Balke and Fomby (1997), Hansen and Seo (2002), and Seo (2003).

\section{Modeling Asymmetries in Price Transmission within a Cointegration Framework}

Engle and Granger (1987) were the first to develop the key concepts of cointegration models. A set of series is said to be cointegrated if each item in the series taken individually is I(1), i.e. nonstationary with a unit root, and some linear combination of the series is stationary, or I(0). Although standard models of cointegrated variables have implicitly assumed linearity and symmetric adjustment, the most recent studies have found that economic variables have an asymmetric cointegrating relationship. Enders and Siklos (2001) argue that the Engle-Granger cointegration test is likely to lead to misspecification errors when the adjustment of the error correction term is asymmetric. They remedy this error by expanding the Engel-Granger two-step cointegration test to incorporate an asymmetric error correction term.

This section introduces the test for cointegration with an asymmetric error correction and explains the way in which an asymmetric error correction model can efficiently be estimated. Suppose two variables $p_{t}^{p}$ and $p_{t}^{w}$ are both $\mathrm{I}(1)$. To examine whether they have an asymmetric cointegrating relationship, the two-step methodology proposed by Enders and Siklos (2001) is employed. These procedures are as follows. First, the ordinary least squares (OLS) is used to estimate the long-run equilibrium relationship between $p_{t}^{p}$ and $p_{t}^{w}$; thus:

$$
p_{t}^{p}=\delta+\beta p_{t}^{w}+\varepsilon_{t}
$$

where $p_{t}^{p}$ and $p_{t}^{w}$ are the producer and world prices, respectively, at time $\mathbf{t}$ for tea; $\delta$ and $\beta$ are parameters to be estimated and $\varepsilon_{t}$ is a random error term with constant variance that can be contemporaneously correlated. If variables $p_{t}^{p}$ and $p_{t}^{w}$ are cointegrated, then the OLS estimates of $\delta$ and $\beta$ are super-consistent, and the speed of convergence is faster than that of stationary variables (Stock, 1987). The existence of a long-run equilibrium relationship will involve the stationrity of $\varepsilon_{t}$; in 
order to investigate this, we need to determine whether $-2<\rho<0$ in the second stage procedure, which is given by

$$
\Delta \varepsilon_{\mathrm{t}}=\rho \varepsilon_{\mathrm{t}-1}+\mu_{\mathrm{t}}
$$

where $\mu_{t}$ is the white-noise distribution, with the residuals from the regression model being used to estimate $\Delta \varepsilon_{\mathrm{t}}$. The rejection of the null hypothesis of no cointegration (i.e. the acceptance of the alternative hypothesis, $-2<\rho<0$ ) implies that the residuals in Equation 2 are stationary, with mean zero. Hence, the long-run equilibrium relationship in Equation 1 is accepted, with symmetric adjustment in Equation 2.

In the second step, it is determined whether or not the disturbance term, $\varepsilon_{t}$, is stationary by considering an asymmetric test methodology in the form of threshold autoregressive (TAR) cointegration model as proposed by Enders and Granger (1998) and Enders and Siklos (2001):

$$
\Delta \varepsilon_{t}=I_{t} \rho_{1}\left(\varepsilon_{t-1}-\tau\right)+\left(1-I_{t}\right) \rho_{2}\left(\varepsilon_{t-1}-\tau\right)+\sum_{i=1}^{k} \gamma_{i} \Delta \hat{\varepsilon}_{t-1}+\mu_{t}
$$

where $\rho_{1}$ and $\rho_{2}$ are coefficients, $\tau$ is the value of the threshold, $\mu_{t}$ is a white-noise disturbance; and $I_{t}$ is the Heaviside indicator such that:

$$
I_{t}= \begin{cases}1 & \text { if } \quad \varepsilon_{t-1} \geq \tau \\ 0 & \text { if } \quad \varepsilon_{t-1}<\tau\end{cases}
$$

They also recommend a two-step estimation approach by first estimating Equation 1 to obtain the residuals, which are then used in Equation 4 to determine $I_{t}$. In the second step Equation 3 is implemented to obtain the estimates of $\rho_{1}$ and $\rho_{2}$. Tong (2012) showed that the OLS estimates of $\rho_{1}$ and $\rho_{2}$ have an asymptotic multivariate normal distribution.

The TAR cointegration model comprises of Equation 1-4 in Enders and Siklos (2001). It is worth noting that the Heaviside indicator function $I_{t}$ depends on the level of $\varepsilon_{t-1}$ in Equation 4. Since the exact nature of the nonlinearity may not be known, Enders and Siklos (2001) consider another kind of asymmetric cointegration test methodology that allows the adjustment to be contingent on the change in $\varepsilon_{t-1}$ (i.e., $\Delta \varepsilon_{t-1}$ instead of the level of $\varepsilon_{t-1}$. In this case, the Heaviside indicator of Equation (4) becomes:

$$
I_{t}= \begin{cases}1 & \text { if } \Delta \varepsilon_{t-1} \geq \tau \\ 0 & \text { if } \Delta \varepsilon_{t-1}<\tau\end{cases}
$$

which is referred to as the momentum-threshold autoregressive (M-TAR) cointegration model.

The asymmetric adjustments in the context of a long-term cointegration relationship can be obtained with two tests. First an F-test is used to examine the null assumption of no cointegration $\left(H_{0}: \rho_{1}=\rho_{2}=0\right)$ against the alternative of cointegration with either TAR or M-TAR threshold adjustment. Let $\Phi$ and $\Phi^{*}$ denote the F-statistics for testing the null assumption $\rho_{1}=\rho_{2}=0$ under 
the TAR and the M-TAR specifications, respectively. The distribution of $\Phi$ and $\Phi^{*}$ are determined by the form of the attractor. The second one is a standard F-test to assess the null assumption of symmetric adjustment in the long-run equilibrium $\left(H_{0}: \rho_{1}=\rho_{2}\right)$. Rejection of the null hypothesis indicates the existence of an asymmetric adjustment process.

The asymmetric error-correction model also exists for $p_{t}^{p}$ and $p_{t}^{w}$ when they are formed in an asymmetric cointegrated relationship. That is:

$$
\Delta p_{t}^{p}=\sum_{s=1}^{k} \alpha_{s} \Delta p_{t-s}^{p}+\sum_{s=1}^{k} \beta_{s} \Delta p_{t-s}^{W}+\gamma_{1} z_{-} p l u s_{t-1}+\gamma_{2} z_{-} \text {minus }_{t-1}
$$

where $p_{t}^{p}$ and $p_{t}^{w}$ are the producer and world prices, respectively; $z_{-} p l u s_{t-1}$ and $z_{-}$minus $s_{t-1}$ are the error correction terms from the cointegration regression defined as:

$z_{-}$plus $_{t-1}=I_{t}\left(p_{t-1}^{p}-\delta-\beta p_{t-1}^{w}\right)$

$z_{-}$minus $_{t-1}=\left(1-I_{t}\right)\left(p_{t-1}^{p}-\delta-\beta p_{t-1}^{w}\right)$

$I_{t}$ is the momentum Heaviside indicator function with the consistent threshold.

\section{Estimation results}

\subsection{Data and Unit root test}

\subsubsection{Data}

The data used in this study are monthly tea world prices and producer prices in Kenya from January 2007 to December 2018. The data periods were chosen because of data availability and also to capture the period of highest pace of agricultural trade liberalization in Kenya. World prices are monthly average prices, compiled by the FAO, extracted from the global information and early warning system (GIEWS) of FAO. Domestic prices considered are monthly average prices paid to the farmers at the farm gate level, collected by the Kenya Tea Development Authority. All prices used herein are expressed in U.S. dollars. They have either been converted here, or were already converted, into U.S. dollar prices. Without using a common currency, the analysis would not be possible since we would not expect there to be any cointegration in prices denominated in different currencies.

The monthly frequency has been chosen because it is the highest frequency that is available over the window of interest. Further, as noted by Barrett and Li (2002), monthly data limit the potential problem of aggregation biases associated with the use of lower frequency data. In addition, the expectation that traders are likely to react to price signals, at least partially, within thirty days favour the use of monthly data. Prices were converted to natural logs prior to estimation and testing. This step is consistent with the majority of studies. In addition, trending series also tend to have differences with growing variance through time, whereas when logged they do not (as in the case of the series explored herein).

\subsubsection{Unit root test}

Before proceeding with the cointegration analysis, we are obliged to perform a unit root test to verify whether the variables under consideration were stationary. In a stationary series, the means and 
variance are constant over time. If a non-stationary series must be differenced $\mathrm{d}$ times before it becomes stationary, it is said to be integrated of order $d$, which is denoted I(d) (Engle \& Granger, 1987). It is only possible for variables to be cointegrated if they are integrated of the same order. Two tests were conducted: the Augmented Dickey-Fuller (ADF) test and the Kwiatkowski-Phillips-Schmidt-Shin (KPSS) test. The combination of the ADF and KPSS tests is a form of confirmatory analysis that has been shown to be more robust in determining the presence of unit roots (Enders \& Siklos, 2001). The ADF test has a null hypothesis of a unit root while the KPSS test has a null hypothesis of no unit root. Table 1 presents the unit root tests. By examining the unit-root and the first-order differences, we find that the null hypothesis of ADF is accepted in level but rejected in first-order difference, and the state of KPSS test is converse. Therefore, all prices are stationary in first-order difference, indicating that these series are both integrated of order one, i.e. I(1), at the $1 \%$ significance level.

Table 1. Unit root and stationary tests

\begin{tabular}{|c|c|c|c|c|}
\hline Variable & \multicolumn{2}{|l|}{ Level } & \multicolumn{2}{|c|}{ First Difference } \\
\hline & ADF & KPSS & ADF & KPSS \\
\hline Producer price & -3.3053 & $2.1958^{\star \star \star}$ & $-9.7233^{\star \star \star}$ & 0.1332 \\
\hline World price & -3.1995 & $3.8969^{\star \star \star}$ & $-10.8923^{\star \star \star}$ & 0.2468 \\
\hline
\end{tabular}

$\star \star \star$ Significance at the $1 \%$ level.

\subsection{Cointegration test}

Based on Table 1, the producer and world prices are considered to be integrated of the same first order; we now carry out further tests to determine the long-run equilibrium relationships between these two variables. We first estimate the symmetric Engle-Granger cointegration as represented by Equation 1 to check whether a long-run relationship between the producer and world prices holds or not. Following the cointegration analysis in the Engle and Granger (1987) sense, the long-run equilibrium relationship between producer and world prices are estimated by OLS. From the estimated OLS regression, we extract the residuals $\left(\mu_{t}\right)$ that will be tested for stationarity. The estimated long-run equilibrium relationship is:

$$
\ln \hat{\mathrm{p}}_{\mathrm{t}}^{\mathrm{p}}=1.112+0.318 \ln p_{t}^{w}+\hat{\mu}_{\mathrm{t}}
$$

where $\ln p_{t}^{p}$ denotes the log-linearized price at the producer level and $\ln p_{t}^{w}$ the log-linearized price at the world level. The t-statistics for the estimated coefficients are presented directly below the parameter estimates in square bracket. These regression results show highly significant parameter estimates. The estimated slope coefficients show the elasticity of producer price with respect to world price and indicate that if world tea price goes up by $1 \%$, then the producer tea price will go up by $0.318 \%$. 
Next, following the Engle-Granger methodology, the residuals $\left(\hat{\mu}_{t}\right)$ in Equation (7) are examined with ADF stationary test without including trend and intercept, as residuals are centered around zero. The estimated residuals obtained are:

$$
\Delta \hat{\mu}_{\mathrm{t}}=-0.017 \mu_{\mathrm{t}-1}
$$

$$
[-3.013]
$$

The $\rho=-0.017$ which implies a t-statistic of -3.013 . The $t$-statistic is beyond (in the negative direction) the $1 \%$ critical value of -2.576 and implies that we reject the null hypothesis of nonstationarity of the residual series. Thus, we conclude that residuals are stationary and thus the variables in the firststep regression are cointegrated, meaning that the long-run relationship between producer tea price and world price is valid. Given the corresponding variables are cointegrated, we further evaluate an asymmetric cointegration test.

\subsection{Asymmetric cointegration test}

The residuals specification in Equation (2) assumes that adjustment process in the long-run is symmetric. Nonetheless, the adjustment can also be asymmetric. In asymmetric adjustment, we establish two partitions for the residuals by classifying them as above threshold or below threshold. To assess asymmetric adjustment in the residuals, first we consider the cointegration joint test (Fstatistics, $\Phi)$ with the null hypothesis of no cointegration, $H_{0}: \rho_{1}=\rho_{2}=0$ that was proposed by Enders and Siklos (2001). If the null hypothesis is rejected, then we examine the null hypothesis of symmetric adjustment, $H_{0}: \rho_{1}=\rho_{2}$ using the standard F-statistic (F-equality). The nonlinear cointegration analysis is conducted using the threshold autoregression models. Four models (i.e., TAR, M-TAR and their consistent counterparts) are examined and the results are reported in Table 2.

For all these specifications, the F-test was employed to examine the null of no cointegration against the alternative of cointegration with either the TAR or M-TAR specification. Because the test does not follow a standard distribution, the Monte Carlo simulation was used to obtain the F-statistics for the null of $H_{0}: \rho_{1}=\rho_{2}=0$. The null of no cointegration can be rejected for all specifications. We see that TAR and M-TAR models have $\rho_{i}$ values with appropriate negative signs as required for stationarity and $\Phi$ statistics which exceed their simulated critical values at the $1 \%$ significance level for all cases, leading us to conclude that that a cointegration relationship exists between international and Kenyan domestic tea prices. These findings support the market integration or the 'one great pool' hypothesis, implying that under the prevailing market liberalization policy, Kenya and world tea markets are integrated.

Table 2. Estimates of TAR and M-TAR cointegration

\begin{tabular}{lllll}
\hline Variable & TAR & TAR-consistent & M-TAR & M-TAR-consistent \\
\hline$\rho_{1}$ & $-0.128^{\star \star}$ & $-0.108^{\star \star \star}$ & $-0.123^{\star \star}$ & $-0.301^{\star \star}$ \\
& $(-2.495)$ & $(-2.712)$ & $(-2.070)$ & $(-2.411)$ \\
$\rho_{2}$ & $-0.140^{\star \star \star}$ & $-0.157^{\star \star \star}$ & $-0.144^{\star \star}$ & $-0.631^{\star \star \star}$ \\
$\tau$ & $(-4.488)$ & $(-2.720)$ & $(-2.475)$ & $(-7.031)$ \\
$\Phi\left(H_{0}: \rho_{1}=\rho_{2}=0\right)$ & 0 & -0.074 & 0 & 0.042 \\
& $7.854^{\star \star}$ & $10.431^{\star \star \star}$ & $8.047^{\star \star}$ & $11.510^{\star \star \star}$
\end{tabular}




$\begin{array}{lllll}F\left(H_{0}: \rho_{1}=\rho_{2}\right) & 2.893 & 2.917 & 3.076 & 13.760^{\star \star \star}\end{array}$

${ }^{\star \star \star}$ and ${ }^{\star \star}$ denote the significance at the $1 \%$ and $5 \%$ level, respectively.

Numbers in parentheses are $t$-statistics.

Once the markets were found to be integrated, a symmetric adjustment hypothesis $\left(\rho_{1}=\rho_{2}\right)$ was tested using the Wald F-Test. However, the null hypothesis of symmetric adjustment in the longterm equilibrium is only rejected for the consistent M-TAR model, suggesting that the price transmission process between the world and the domestic tea market is asymmetric. More precisely, the world market price decrease and increase are found to be exerting different impacts on producer price. Focusing on the results from the consistent M-TAR model, the F-test for the null of no cointegration has a statistic of $\mathbf{1 1 . 5 1 0}$ and it is highly significant at the $1 \%$ level. Thus world market prices and producer prices in Kenya are cointegrated with threshold adjustment. Furthermore, the F statistic for the null hypothesis of symmetric price transmission has a value of $\mathbf{1 3 . 7 6 0}$ and it is also significant at the $1 \%$ level. Therefore, the adjustment process is asymmetric when prices of world market and domestic market adjust to achieve the long-run equilibrium.

The point estimate for the price adjustment is $\rho_{1}=-0.301$ for positive shock and $\rho_{2}=-0.631$ for negative shock. In this regard, the higher magnitude of $\left|\rho_{2}\right|$ compared to $\left|\rho_{1}\right|$ indicates that negative price deviations (squeeze of market margin) are adjusted immediately, more quickly than for the positive price deviations (expansion of market margin). In line with the direction of the price movement (from world market to domestic market), the squeeze of market margin reflects the world price increases while the market margin expansion reflects the world price decreases. Thus, a higher value of $\left|\rho_{2}\right|$ compared to $\left|\rho_{1}\right|$ suggests that negative deviations from long-run equilibrium resulting from decreases in world prices are passed on quickly to domestic producers whereas positive deviations resulting from increases in world prices are transmitted at a slower rate.

The estimated coefficients for deviations above the threshold $\rho_{1}$ are lower than the estimated parameters for discrepancies below the threshold $\rho_{2}$, indicating that a higher speed of adjustment towards the long-run equilibrium takes place when the price spread deviates below the equilibrium. Positive deviations from the long-run equilibrium resulting from increases in the world price or decreases in producer prices $\left(\Delta \hat{\varepsilon}_{t-1} \geq-0.042\right)$ are eliminated at $30.1 \%$ per month. Negative deviations from the long-run equilibrium resulting from decrease in the world price or increases in the producer prices $\left(\Delta \hat{\varepsilon}_{t-1}<-0.042\right)$ are eliminated at a rate of $63.1 \%$ per month. In other words, positive deviations take about 3 months (1/0.301=3.32 months) to be fully digested while negative deviations take 1.5 months only. Therefore, there is substantially slower convergence for positive (above thresholds) deviations from long-term equilibrium than negative (below threshold) deviations.

\subsection{Asymmetric error-correction modeling}

Given the consistent MTAR model confirmed by the presence of asymmetry in the price transmission process, the error correction terms are constructed using Equations (3) and (5). The asymmetric error correction model with threshold is estimated in Equation (6) and the results are reported in Table 3. The estimates reveal asymmetric adjustments, specifically, the $t$-statistic indicate that the coefficients of the positive and negative error terms (i.e. Z_plus and Z_minus) are significantly 
different from zero at conventional levels, indicating that changes in producer prices respond to both positive and negative deviations in the long-run price equilibria.

Table 3. Theshold error correction model

\begin{tabular}{lll}
\hline & Producer price & \\
\cline { 2 - 3 } & Coefficient & t-statistic \\
\hline Z_plus & $-0.311^{\star \star \star}$ & -3.665 \\
Z_minus & $-0.659^{\star \star}$ & -2.180 \\
\hline
\end{tabular}

The values are significantly different from zero at ${ }^{\star \star \star} 1 \%$ and ${ }^{\star \star} 5 \%$ levels.

Focusing on the adjustments in the producer prices, the point estimates of the adjustment coefficients reveal that for a single unit negative change in the deviation from the equilibrium relationship created by changes in the world market prices, producer prices adjust by $65.9 \%$. On the other hand, producer prices adjust so as to eliminate approximately $31.1 \%$ of any positive change in deviation from the equilibrium created by change in the deviation from the equilibrium created by changes in the world market prices. These findings indicate that after the reform of agricultural trade liberalization, adjustments between the world market prices and producer prices towards a long-run equilibrium relationships are more rapid when changes in the deviation are negative, than when they are positive. This findings suggest that policy reforms has exposed tea producers to the concentrated tea world market, where key players tend to pass on prices that squeeze their margins, but reluctant to pass on those that increase the margins.

\section{Conclusion}

Tea is Kenya's leading export commodity. Over the past three decades, Kenyan government has implemented policy reforms in the tea sector to integrate tea farmers into international markets. These policy reforms were aimed to benefit domestic tea farmers, as market integration allows them to respond to market signals and make optimal production decisions. Given that policy reforms in the tea sector were geared towards getting prices right for farmers, an issue of economic significance is the extent to which changes in world tea prices are transmitted to domestic producers. This study examines the transmission of tea prices from the world market to domestic markets in Kenya.

In this study, we applied the concept of threshold cointegration to understand price transmission. The concept of threshold cointegration has become popular in applied economic research. It captures the fact that equilibrium adjustment does not have to occur at every instant in series and while cointegration may be present, a band may exist such that factors such as transaction costs may be too high to make equilibrium adjustments justified. We make use of threshold cointegration techniques developed by Enders and Siklos (2001) to account for the possible nonlinearity and asymmetry in the transmission of price changes from world tea market to producer prices in Kenya.

The empirical evidence indicates that there is a close link between the Kenya's tea price and its international counterparts under the current period of market liberalization, which renders support to the "one great pool" hypothesis. This implies that Kenya has become a part of the integrated world tea market after a series of policy reforms in the agricultural sector over the past three decades. The integration into the world market demonstrates the efficiency of Kenya's tea sector and implicitly validates the policy reforms. While there is evidence of co-movements between world tea prices and 
producer tea prices, the evidence of non-linear co-movement was significant. The evidence of the existence of threshold cointegration, which could be induced by the presence of high transaction costs, was found in transmission of price changes from the world tea market to domestic market in Kenya.

The threshold cointegration analysis reveals that in the long term positive deviations of price spread between the two markets take about three months to be fully digested, while negative deviations take less than one and half months. Similarly, in the short term, the error correction model reveals that tea producers need three months to fully digest positive shocks but one and half shocks for negative shocks. Thus, the transmission between the prices of world tea market and Kenyan domestic market has been asymmetric in both long term and short term, suggesting long-run and short-run dynamic inefficiencies and presence of transaction costs. Thus, our results provide important policy implications for Kenyan tea markets, namely that policies aimed at reducing transaction costs should be encouraged to further improve market efficiency. So, from a policy standpoint, if Kenyan government implements only policies related to removing tariff barriers without taking into account the non-tariffs related barriers the effectiveness of such policies for greater market integration would likely to be compromised.

\section{Competing interests}

The author declare that he has no competing interests

\section{Acknowledgments}

The author is grateful to anonymous referees for their useful comments and suggestions for revising the paper. Any remaining errors are my own.

\section{Availability of data and materials}

The data were extracted from the global information and early warning system (GIEWS) of FAO

\section{Funding}

This work has been part of doctoral research funded by DAAD

\section{References}

Abdulai, A. (2000). Spatial price transmission and asymmetry in the Ghanaian maize market. Journal of development economics, 63(2), 327-349.

Balcombe, K., Bailey, A., \& Brooks, J. (2007). Threshold effects in price transmission: the case of Brazilian wheat, maize, and soya prices. American Journal of Agricultural Economics, 89(2), 308-323.

Balke, N. S., \& Fomby, T. B. (1997). Threshold cointegration. International economic review, 38(3), 627645.

Baquedano, F. G., Liefert, W., \& Shapouri, S. (2011). World market integration for export and food crops in developing countries: a case study for Mali and Nicaragua. Agricultural Economics, 42(5), 619-630.

Barrett, C. B., \& Li, J. R. (2002). Distinguishing between equilibrium and integration in spatial price analysis. American Journal of Agricultural Economics, 84(2), 292-307.

Enders, W., \& Granger, C. W. J. (1998). Unit-root tests and asymmetric adjustment with an example using the term structure of interest rates. Journal of Business \& Economic Statistics, 16(3), 304311. 
Enders, W., \& Siklos, P. L. (2001). Cointegration and threshold adjustment. Journal of Business \& Economic Statistics, 19(2), 166-176.

Engle, R. F., \& Granger, C. W. (1987). Co-integration and error correction: representation, estimation, and testing. Econometrica: journal of the Econometric Society, 251-276.

Fiamohe, R., Alia, D. Y., Bamba, I., Diagne, A., \& Amovin-Assagba, E. (2015). Transmission of rice prices from Thailand into west african markets: the case of Benin, Mali, and Senegal. Journal of African Business, 16(1-2), 128-143.

Goodwin, B. K., \& Piggott, N. E. (2001). Spatial market integration in the presence of threshold effects. American Journal of Agricultural Economics, 83(2), 302-317.

Hansen, B. E., \& Seo, B. (2002). Testing for two-regime threshold cointegration in vector errorcorrection models. Journal of econometrics, 110(2), 293-318.

Korale Gedara, P., Ratnasiri, S., \& Bandara, J. (2016). Does asymmetry in price transmission exist in the rice market in Sri Lanka? Applied Economics, 48(27), 2491-2505.

Mai, T. C., Shakur, S., \& Cassells, S. (2018). Testing vertical price transmission for Vietnam's Robusta coffee. Australian Journal of Agricultural and Resource Economics, 62(4), 563-575.

Mighri, Z., \& Mansouri, F. (2016). Asymmetric price transmission within the Argentinean stock market: an asymmetric threshold cointegration approach. Empirical Economics, 51(3), 1115-1149.

Mofya-Mukuka, R., \& Abdulai, A. (2013). Policy reforms and asymmetric price transmission in the Zambian and Tanzanian coffee markets. Economic Modelling, 35, 786-795.

Seo, B. (2003). Nonlinear mean reversion in the term structure of interest rates. Journal of economic dynamics and control, 27(11-12), 2243-2265.

Shen, C.-H., Chen, C.-F., \& Chen, L.-H. (2007). An empirical study of the asymmetric cointegration relationships among the Chinese stock markets. Applied Economics, 39(11), 1433-1445.

Shrinivas, A., \& Gómez, M. I. (2016). Price transmission, asymmetric adjustment and threshold effects in the cotton supply chain: a case study for Vidarbha, India. Agricultural Economics, 47(4), 435444.

Stock, J. H. (1987). Asymptotic properties of least squares estimators of cointegrating vectors. Econometrica: journal of the Econometric Society, 1035-1056.

Tong, H. (2012). Threshold models in non-linear time series analysis (Vol. 21): Springer Science \& Business Media. 